\title{
Application of Peer Education in the Freshman Adaptability Problem
}

\author{
Miao Tian ${ }^{1}$, \\ ${ }^{1}$ International Education College \\ Hebei Finance University \\ Baoding, China
}

\author{
Bing-jie Tian $^{2}$ \\ ${ }^{2}$ Department of Economic Trade \\ Hebei Finance University \\ Baoding, China
}

\begin{abstract}
Adolescent students enter university from high school may face some adaptability problems in study, life and psychology because of various reasons, and it will affect their long-term development in the future. Adaptive education of colleges and universities in China has carried out, but there are some problems in the education content and actual effect. Take the peer education into the education of freshmen's adaptability, use peer influence to improve ability to adapt to the environment of freshmen in the study, life and thought education continuously.
\end{abstract}

Keywords: freshmen; peer education; Adaptability

\section{INTRODUCTION}

Peer education originated in the field of psychology research, around the early sixties of the 20th century, American psychologist had reported the peer counseling on psychological counseling, mainly used for the diagnosis and treatment of psychological problems. "The original meaning of peer education is refers to the people with the same background or common language to share information, ideas or behavior skills together to achieve the educational goals of education method" ${ }^{[1]}$ The problem of adaptation of freshmen mainly refers to the situation that college freshmen can't fit into the study, life and psychology after entering college life. With the continuing concerns about the college students' mental health problems, more and more schools began to carry out the necessary educational activities to help them adapt to university life better.
"Adaptability is the individual's effective response, adaptation to the natural and social environment. Including individual life, maintain their own life, to meet the cultural requirements of the individual and the community, etc." ${ }^{[2]}$ About the problem of "adaptability", the scholars in Holland have evaluated the adaptability of college students from eighty aspects: study, social, emotional adaptation, and dependence on school in the four's in twentieth Century. ${ }^{[3]}$ We emphasize that carrying out adaptive education in the freshmen is to help them join in a new environment with the fastest speed, in order to achieve better development.

\section{A freshman adaptability problems of education now}

\subsection{The main performance of the freshmen adapt to the} problem

2.1.1 Lack of learning motivation, learning objectives are not clear

Many freshmen, passed the cruel college entrance examination, think the end of the college entrance examination is the end of learning, There may be some deviations of their learning attitudes. They also think learning is not the main task when they go to college, so the goal of learning is not so clear for them, they even do not know what the real goal of learning for themselves. Lack of necessary learning motivation may cause them to indulge in online games or other bad habits; it will give them an extremely unfavorable effect on their physical or mental health development. According to tencent Michael thought level 2010 college freshmen monthly tracking " $61 \%$ of 
undergraduates think main problem is the study of the problems after the entrance, first among learning problems in the lack of learning motivation". There are more boys than girls, and easy to learning problems, $62 \%$ and $58 \%$ respectively", ${ }^{[4]}$

\subsubsection{Part of the students' living ability is weak}

Many freshmen may did not experience the living accommodation before entering the university campus, they are taken care of very thoughtful at home by their parents, although not as that hand clothing to eat a ready-cooked meal, there are some lack in life self-care ability. The problems are mainly embodied in some students from urban family that the life condition is superior, they depend on their parents too much at home, resulting in they cannot adapt the college life when they enter the college at first. For example, in some basic life issues such as the dormitory personal hygiene cleaning and washing clothes and it's like can reflect the student's ability to adapt their life easily. On the other hand, some students who go to university from one provincial to another cannot adapt the weather or diet, the situation is worthy of attention.

2.1.3 Interpersonal relationship is not harmonious, the psychological ability is weak

After entering the University, every freshman first face with a strange environment, including the campus peripheral environment and internal environment that get along with people. They are exposed to strange teachers and foreign students, they need gradually established its own network of relationships in such an unfamiliar environment, for some students who are more introverted and dissocial, They're not too good at joining in a new collective relatively in a short time. That is the main reason $t$ why a lot of new students came into the University and contact their high school classmates more. So it is easy to generate adaptability problems such as interpersonal harmony. Interpersonal relationship are not be harmonious can make the new students have a pessimistic mood easily, if not timely adjustment, it is easy to suppress or even form a certain psychological problems. And there are also some students in senior high school is outstanding, after entering the university, they will find that there are more and more excellent people appear in various activities, someone whose psychological bearing ability weak will get lost on personal value judgment which leads to some adaptability problems.

\subsection{Problems in the University's adaptive education}

2.2.1 The content of education is too simple and the emphasis on Moral Education

At present, the major colleges and universities in our country have carried out for freshmen education activities, including professional introduction, learning the history of school, experience exchange and theme class meeting and all kinds of theory or practice activities, the purpose is to help freshmen to have a macro aspects understanding for their new school and special industry and future learning and life goal at the beginning of entering school. They can decide the learning objectives to keep positive attitude to complete their college life. But in a general view, the content of these adaptive education is too simple, most of which are some of the programming of the things, Whether it is a professional introduction or exchange of experience is not enough to go into the new students needs to satisfied the real task that to improve themselves. In addition, in the education of Freshmen's adaptability of content, the content of moral education accounted for a large proportion, we always hope that students can establish correct life view, values in the new learning process, this is of course essential, but if the content of overly didactic stereotype ,it will not conducive to student learning.

\subsubsection{The lack of persistence in adaptive education cause} that it cannot form a long-term impact

Adaptive education of freshmen not only in school a week or a month to complete, this is a relatively long-term work, Less than six months, more than a year can we really make a student who has a weak adaptive ability learn to gradually accept school, accept the new life. But in the process of carrying out adaptive education in many colleges 
and universities, the activities are more mere formality, only in the first month of the school has a number of new activities, and then there is nothing, "According to the results of a questionnaire survey for students in 7 universities in Chongqing in 2010, 'the time of carrying out adaptive education lasted for up to a month 'form of 41 . $07 \%$, 'two months' form $6.83 \%$ and 'more than two months' of only $1.3 \% .{ }^{[5]}$ This fully reflects the lack of adaptability of the new students in our country, so it cannot form a profound impact on the students in the long term. Of course, it is an important reason that there is not enough full-time counselors in the university, it is also affect the sustained adaptability education of freshmen. The new students come into the university, and they contact with their full-time counselors mostly in their life, at present Chinese instructors and students than generally remains in 1:200, which makes many counselors have a hefty workload, and they cannot compete successfully for the education of freshmen's adaptability.

\section{The application and significance of peer education in the new student's adaptive education}

\subsection{Set an example in the study, and encourage them to complete their studies.}

In the process of developing peer education, some colleges and universities are mostly based on the "peer counselors", they select some high grade students or graduate who are outstanding in academic achievement and work ability in the same major with the freshmen. The peer counselors should be enthusiasm and sense of responsibility of students; they served as a part-time instructor and cooperate with full-time counselor together for the freshmen adaptability education. These peer counselors is better in study firstly, they can use their own instance to convey a positive learning and enterprising spirit to the freshmen. Setting an example In the study solves the problem of the freshmen in the study of adaptability firstly. Whether it is lack of learning motivation and learning objectives is not clear, these peer counselors who with similar age and similar experience are able to educate and guide them from their own positive experience. Compared to the past few full-time counselors, the peer counselors have a better understanding of the professional some learning, it is easier to mix with the new, promote exchanges.

\subsection{Become a new partner in life, promote communication between students}

Compared with traditional full-time counselors the seniors peer counselors is more affinity, closer to the student's actual life and help them solve practical problems. "According to Qianjiang college, Hangzhou Normal University School of economics and management professional e-commerce group feedback questionnaire data show that: $80 \%$ of the students said 'peer between easy to communicate, there is a sense of identity, a sense of security', $66.7 \%$ of the students said 'open communication between peers, increase the mutual cohesion', $68 \%$ of the students hope peer activities can often hold,.."[6] It shows that most of the students are more accept their similar age peer counselors, and the young people together will have more common language, they can communicate smoother in the life. Whether it is the unsuccessful love or roommate relations not harmonious, or homesick thoughts, the peer counselors can talk with them, so that make the freshmen variety of negative emotions have a good channel to vent, discover some possible problems and correct it.

\subsection{Construct a new management mode to make up for the lack of full-time Counselors}

The adaptability education for Freshmen's in Colleges and universities should be an important part for students to carry out quality education, it is related to the ability of students exchanging from high school to college life successfully, it has a far-reaching influence in students, whether they can gradually matured in the university for four years in school. So constructing a new mode of management education from the peer education, make up the lack of full-time counselors are one of the most important contents in the freshmen's adaptability problems 
peer education. "Benign interaction between the peers, and outstanding people external touch and stimulate will be easier to triggered new thinking and consciousness, therefore, the role and value of self peer education were also more prominent" ${ }^{1[1]}$ In the process of solving the new adaptive problem, we must be clear about the goal, that is to create good adaptive environment for students, accelerate to the speed of the new environment, quickly integrate into university life and create a new high level of personal development. Construct a working mechanism that peer counselors and full-time counselors can work in a mutual cooperation, on the one hand to make up for the lack of full-time counselor staff strength, on the other hand, it is a kind of responsible activities for the students. From the peer education of freshmen and outstanding seniors to promote communication, guide the clear goal and motive of college life.

\section{Note of the peer counselor education}

\subsection{We should pay attention to the selection and training of peer counselors}

Peer counselors are mostly from in the senior or graduate students; they are at the new students' age and have a more similar experience with the freshman that is what we valued. The peer counselors can integrate into the freshmen better and help them with some question in their life. It can make them adapt to college life better and easier. But in the selection of peer counselors' work, we must increase the degree of attention, to select some outstanding achievement, outstanding ability to work, firm ideological and political ideas and working enthusiasm high students as peer counselors. As an important link connecting students and school education, as an important part of peer education, the selection and training work of peer counselors is the precondition and basis of adaptive education for freshmen.

\subsection{We should continue to strengthen the assessment and incentive mechanism for peer counselors}

Selection of outstanding high school students or graduate students as a peer counselor, for every students who can served as peer counselors of the students, on the one hand, this is a kind of affirmation for their daily work and study, and can provide them an exercise and enhance opportunities for interpersonal and communication skills, on the other hand, in their work and process, scientific evaluation and incentive mechanism is also essential. We must ensure that every student in the peer counselor can get some harvest from work as a peer counselor, but also use some quantitative standards to demand them on the peer counselor quality of the work, to ensure the effectiveness of adaptive education for freshmen.

\subsection{Do a good job with full-time counselors of the joint work}

With some of the best students as peer counselors doesn't mean that the full-time counselor can push all the work to peer counselors, full-time instructor and peer counselors should complement and promote each other, they cannot be both opposition. Therefore, after setting up a peer counselors, it is essential that we should take a in science division of their work besides the necessary selection, training and management of the peer counselors. We should take some measures to make both sides understand its responsibility and help each other and achieve a mutual cooperation. When the peer counselors in the face of graduation or looking for a job, they must do a good exchanges and communication work with the full-time instructors in terms of specific new education, to ensure the smooth development of the work, and truly serve the students.

\section{CONCLUSION}

The new students in current era go to the university are gradually become "post-95" after "post-90", they are young and energetic, they have their own ideas and thoughts about our life, but also may be more vulnerable. Because of their superior childhood living conditions compared with the former students, they may show a bigger problem in adapting in the University in this new environment. Most of them live in a life that parents love them too much; they 
may be able to take care of themselves better when they are in the new school. Making full use of the new and intimate relationships between peer counselors and the new students, starting from the peer education can help us solve the problem of freshmen's adaptability problems in theory or practice. In fact, the point of view is feasible. People always well at to listen and accept the views thoughts conveyed from the people who is age and experience similar with themselves. Making full use of the advantages of peer counselors, and combining with the full-time counselors work, so that the two sides complement each other, enhance the effectiveness of adaptive education for freshmen, to ensure that every entering freshmen at the university are able to adapt to college life in the shortest possible time, and adjust the goal of individual life, the role of rapid change, resulting in finding their university point to achieve the full and healthy development of themselves.

\section{References:}

[1]Xu Zhanlu.The Research of Peer Education System in the Adaptability of College Freshmen[J].Journal of Jiangxi Institute of Education (social Sciences),p39,2009(10).

[2]Huang Xiting. Concise Dictionary of Psychology.[M]. He Fei: An Hui People's Publishing House, p348. 2004.

[3]Dwyer, J.O.A Historical Look at the Freshman Year Experience.Upcraft, M.L.\&Garder,J.L.The Freshman Year Experience. San Fransico: Jossey-Bass, p24-p39.1989,

[4]Kang Lifang. College Freshmen Adaptability Problem and Countermeasures to Huazhong Normal University Undergraduate 2010 Freshmen.[D].Shanghai.Huazhong Normal University master's thesis. In May 2012:p14.

[5]Guo Chunming. At Present Our Country College Students Adaptability Education the Main Problems and Countermeasures Research.[D]. Chongqing..Southwest university master's thesis.p25.p26.2012,

[6] Zuo Kaixuan,Shan Ya. Peer Education in Moral Education for University Students [J]. Journal of Zhejiang Institute of Media and Communications,p102,2011(6) 